\title{
大規模副作用データベースと計算毒性学に基づく副作用予測
}

\author{
植沢芳広
}

\section{Adverse Effect Predictions Based on Computational Toxicology Techniques and Large-scale Databases}

\author{
Yoshihiro Uesawa \\ Department of Clinical Pharmaceutics, Meiji Pharmaceutical University; \\ 2-522-1 Noshio, Kiyose, Tokyo 204-8588, Japan.
}

(Received July 17, 2017)

\begin{abstract}
Understanding the features of chemical structures related to the adverse effects of drugs is useful for identifying potential adverse effects of new drugs. This can be based on the limited information available from post-marketing surveillance, assessment of the potential toxicities of metabolites and illegal drugs with unclear characteristics, screening of lead compounds at the drug discovery stage, and identification of leads for the discovery of new pharmacological mechanisms. This present paper describes techniques used in computational toxicology to investigate the content of large-scale spontaneous report databases of adverse effects, and it is illustrated with examples. Furthermore, volcano plotting, a new visualization method for clarifying the relationships between drugs and adverse effects via comprehensive analyses, will be introduced. These analyses may produce a great amount of data that can be applied to drug repositioning.
\end{abstract}

Key words_ computational toxicology; adverse effect; database; prediction model; quantitative structure-activity relationship

はじめに

近年，様々な研究領域において自発報告に基づく 副作用の大規模なデータベースが利用されるように なってきた. 1,2) これらの情報源は, 市販医薬品によ る副作用の発現傾向を帰納的に把握するための優れ たツールとなる．創薬段階の研究開発においても新 薬がドロップアウトするリスクとして薬物の毒性・ 副作用は最も大きな要因の 1 つである. ${ }^{3)}$ 相互作用 を含む副作用により市販後に新薬が市場から撤退す る事例も決して少なくない。化学構造などの医薬品 側の情報から副作用の予測はこれらのリスクを回避 する上で有効な手段になり得ると考えられる．臨床 上の安全性管理においても, 新薬のような市販後調 査が不十分な医薬品や危険ドラッグのような副作用 情報が欠落している化合物群に対して，このような

明治薬科大学臨床薬剤学研究室 (厂204-8588 東京都清 瀬市野塩 2-522-1)

e-mail: uesawa @my-pharm.ac.jp

本総説は, 日本薬学会第 137 年会シンポジウム S07 で

発表した内容を中心に記述したものである.
副作用予測法は大きく貢献するものと考えることが できる．計算毒性学は，このような化学構造からの 薬物の毒性・副作用予測を研究課題の 1 つとする学 術領域である.

筆者らは副作用発現リスクのシグナルとしてオッ ズ比及び正確検定を用い，種々の医薬品と副作用の 解析を実施してきた. ${ }^{4-7)}$ 本稿では, 新規に考案し た副作用情報の表現方法を紹介するとともに，計算 毒性学的検討に上記の医薬品副作用データベースを 援用することによる新規副作用予測法を提案する.

\section{1. 有害事象自発報告データベース JADER}

2003 年に副作用の報告義務に関して薬事法の改 正がなされた（第 77 条の 4 の 5 第 3 項）。同法によ り，2004 年 4 月より独立行政法人医薬品医療機器 総合機構 (Pharmaceuticals and Medical Devices Agency; PMDA）への医薬品有害事象の報告が義務 づけられることとなつた。PMDA に蓄積された副 作用・有害事象関連デー夕は，2012 年から有害事 象自発報告データベース (Japanese Adverse Drug Event Report database; JADER）として一般公開さ 


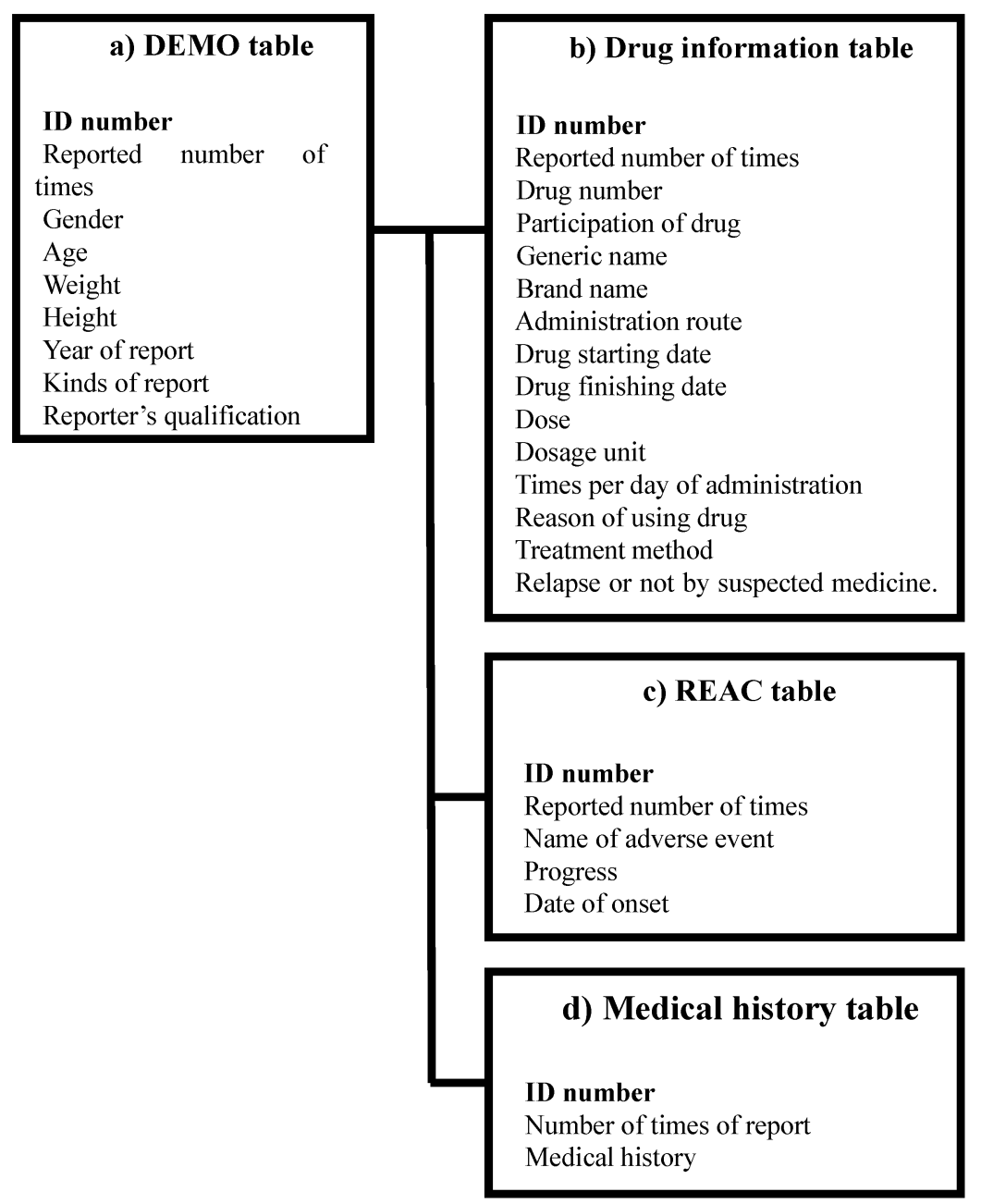

Fig. 1. Four Information Tables Included in JADER

れている. ${ }^{8)}$ JADER は, 副作用の発現傾向を把握 するために活用し得るわが国最大のデータベースで ある.PMDA のホームページから Fig. 1 に示す 4 種類のテーブル（症例一覧テーブル，医薬品情報 テーブル，副作用テーブル，原疾患テーブル）が csv ファイル形式でダウンロードできる. ユーザは これらのファイルを適宜組み合わせることによつ て，医薬品と副作用の関連等を解析することができ る。本稿執筆時点において，JADER には 20042016 年の副作用関連自発報告データが登録されて おり, 症例件数 45 万件, 累積副作用件数 71 万件, 投与別薬物件数 290 万件, 累積原疾患件数 90 万件 を含む大規模なデータベースとなっている．これら の登録件数は 1 年間に 4 回更新される. 本デー夕 ベースは，OTCを含め，日本で臨床使用されてい るすべての市販医薬品の副作用を網羅している. Figure 2 に示すように，薬事法改正により登録が開

始されて以来，その登録件数はやや加速度的に増加 しており，更なる大規模データへと成長を続けてい る.

2. Volcano プロットとドラッグリポジショニング JADER のような副作用の自発報告データベース には，副作用を発現しない「正常な」患者の情報は 存在しない。すなわち，JADER に格納されたデー 夕の解析からは，ある薬物 A が示す副作用 B の発 現率を算出することができない。そこで，薬物 $\mathrm{A}$ と副作用 $\mathrm{B}$ の間の相関を吟味するために報告オッ

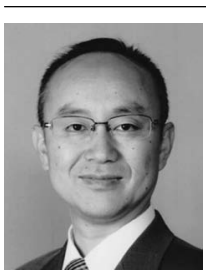

植沢芳広
明治薬科大学臨床薬剂学研究室 - 准教 授. 京都大学薬学研究科博士課程修 了. 毒性予測コンペティションである NIH-Tox21 DATA Challenge 等にて入 賞. 医薬品・化学品の生理作用を理解 するために計算機化学的なアプローチ を試みている。 


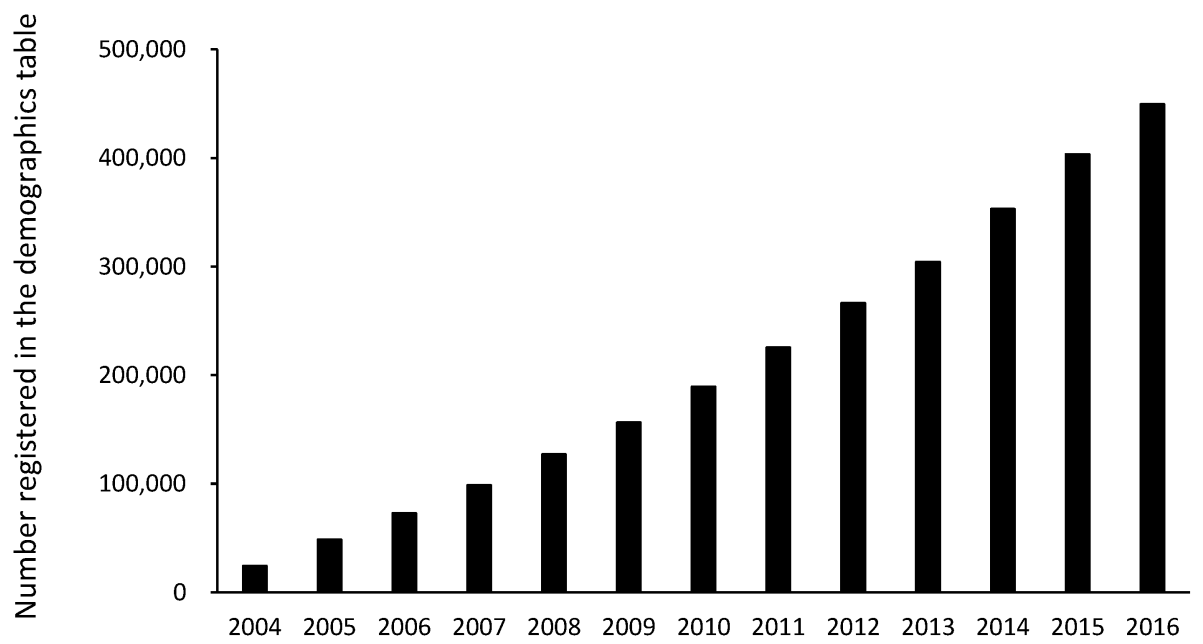

Fig. 2. Annual Changes of Numbers Registered in the Demographic Table of JADER

\begin{tabular}{|l|c|c|}
\hline & Hiccups & non-Hiccups \\
\hline $\begin{array}{l}\text { Reports with the } \\
\text { suspected medicine }\end{array}$ & a & c \\
\hline All other reports & b & d \\
\hline
\end{tabular}

ROR (reporting odds ratio $)=(\mathbf{a} / \mathbf{b}) /(\mathbf{c} / \mathbf{d})=\mathbf{a d} / \mathbf{b c}$

Fig. 3. Cross-tabulation and Calculation Formula of the ROR of Hiccups

This figure was cited from Ref. 7).

ズ比などのシグナル検出指標を使用する. ${ }^{9)}$ Figure 3 に吃逆と薬剤に関するクロス集計表を例示する. ${ }^{7}$ 集計表の作成のためには医薬品情報テーブルと副作 用テーブルを識別番号に基づいて結合し，適切に重 複例を排除した結合テーブルを作成する．報告オッ ズ比は，このクロス集計表に記載された 4 種類の度 数（a, b, c, d）の偏りを表現するシグナル検出指標 として使用される，さらに，これら 4 種類の度数の 偏りから薬物と副作用の間に有意な統計上の関連が 認められるか否かを計算する手法として，カイ 2 乗 検定やフィッシャーの正確検定が挙げられる．特に フィッシャーの正確検定は，クロス集計表における 各マスに $0,1,2$ といつた極めて小さな報告度数が 入った場合においても有効であるため, 副作用デー 夕を網羅的に検討する場合に好都合である.

報告オッズ比と正確検定から得られる危険率 $(p$ 值）の組合せは，医薬品と副作用との間の関係を表 現する上で有用である. 報告件数の少ない医薬品・ 副作用の関係から報告オッズ比を計算する場合, 統 計的重要性が低いにもかかわらず極めて大きな，若 しくは小さな值を与えることが少なくない。そこ
で，筆者らは対数報告オッズ比 $(\operatorname{lnOR})$ と $p$ 值の 常用対数 $[\log (p$ 值 $)]$ の網羅的な計算結果から散 布図を作成し, 統計的に重要かつオッズ比の大きな （小さな）医薬品一副作用の組み合わせの検討に使 用している. ${ }^{5-7)} こ の$ 散布図は，バイオインフォマ ティクス領域においてマクロアレイデータ等の解析 に用いられている volcano プロットに相当する。例 として, Fig 3 のクロス集計表を医薬品名毎に網羅 的に作成することによる薬剤性吃逆の解析事例を示 す.7) Figure 4 に吃逆を惹起する薬物の解析に使用 した volcano プロットを示す。散布図の右上方に分 布する薬物は，薬剤性吃逆の副作用を惹起する可能 性が高いことが分かる。，一方，解析対象によっては 左上方に分布する薬物が見い出されることもある.

このような場合，それらの薬物を服用している患者 は解析対象としている副作用を相対的に惹起し難い と解釈できる．併用薬や患者背景等による交互作用 に十分に注意を払う必要があるが，これらの薬物は 当該副作用を抑制する効果を有している可能性があ る.これらの情報は, 薬物の新しい用途を開拓する ドラッグリポジショニングに応用可能であると筆者 は考えている.

\section{3. 計算毒性学}

莫大な費用を要する長期間の創薬過程において, 新薬の上市に失敗する主要な要因の 1 つに副作用・ 毒性発現リスクがある。創薬の初期段階において, 候補化合物の毒性・有害性を，コンピュー夕技術を 用いて推定するための技術に関する研究領域が計算 毒性学（Computational toxicology）である. ${ }^{10)}$ 計 


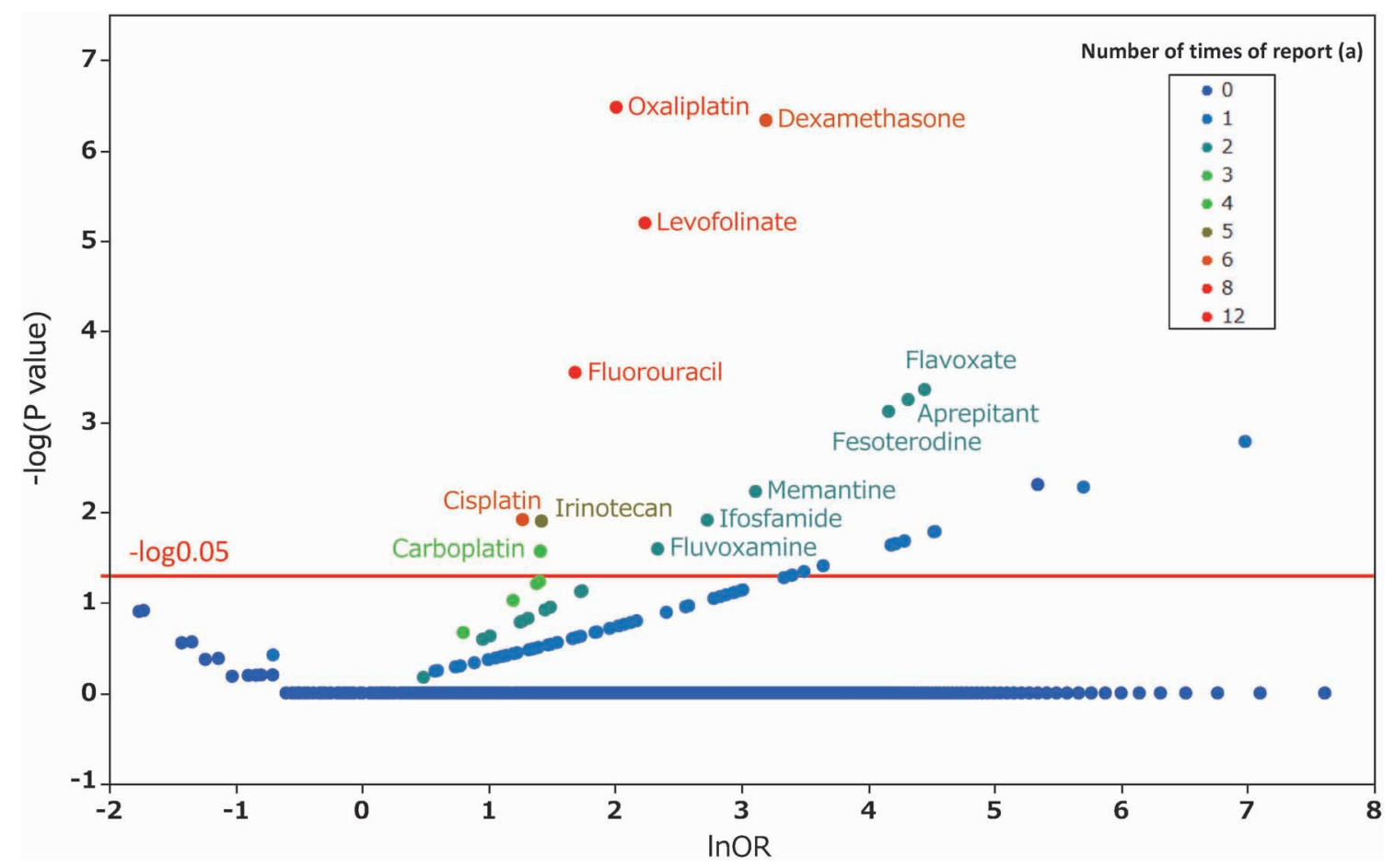

Fig. 4. Volcano Plot: Medicines Associated with Hiccups This figure was cited from Ref. 7).

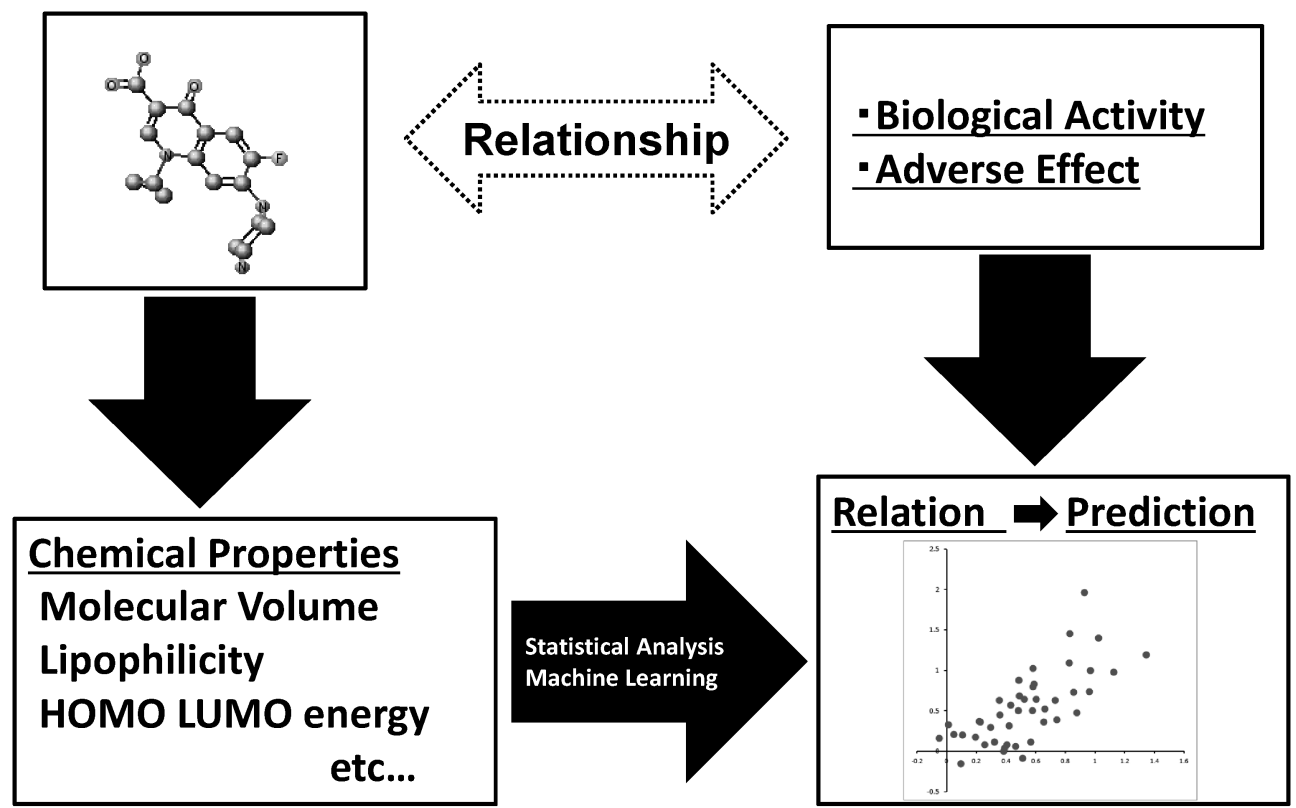

Fig. 5. Concept of Quantitative Structure-Activity Relationship Analysis

算毒性学は, 化学物質が惹起する毒性の予測及び毒 性発現機序の解明を目的とした数学的・計算機科学 的モデルの適用，と定義される。.In vivo/in vitro 実験系を使用せずに薬物等の有害性を予測すること が本領域の重要な目標の 1 つであることから，化学 構造情報を用いた毒性予測モデルの構築が試みられ
ている.

4. 定量的構造活性（副作用）相関

定量的構造活性相関（quantitative structure-activity relationship; QSAR）解析は，化学構造情報と酵 素活性阻害能や受容体親和性をの相関を観察する解 析法である. ${ }^{11,12)}$ 化学構造からオクタノール水分配 


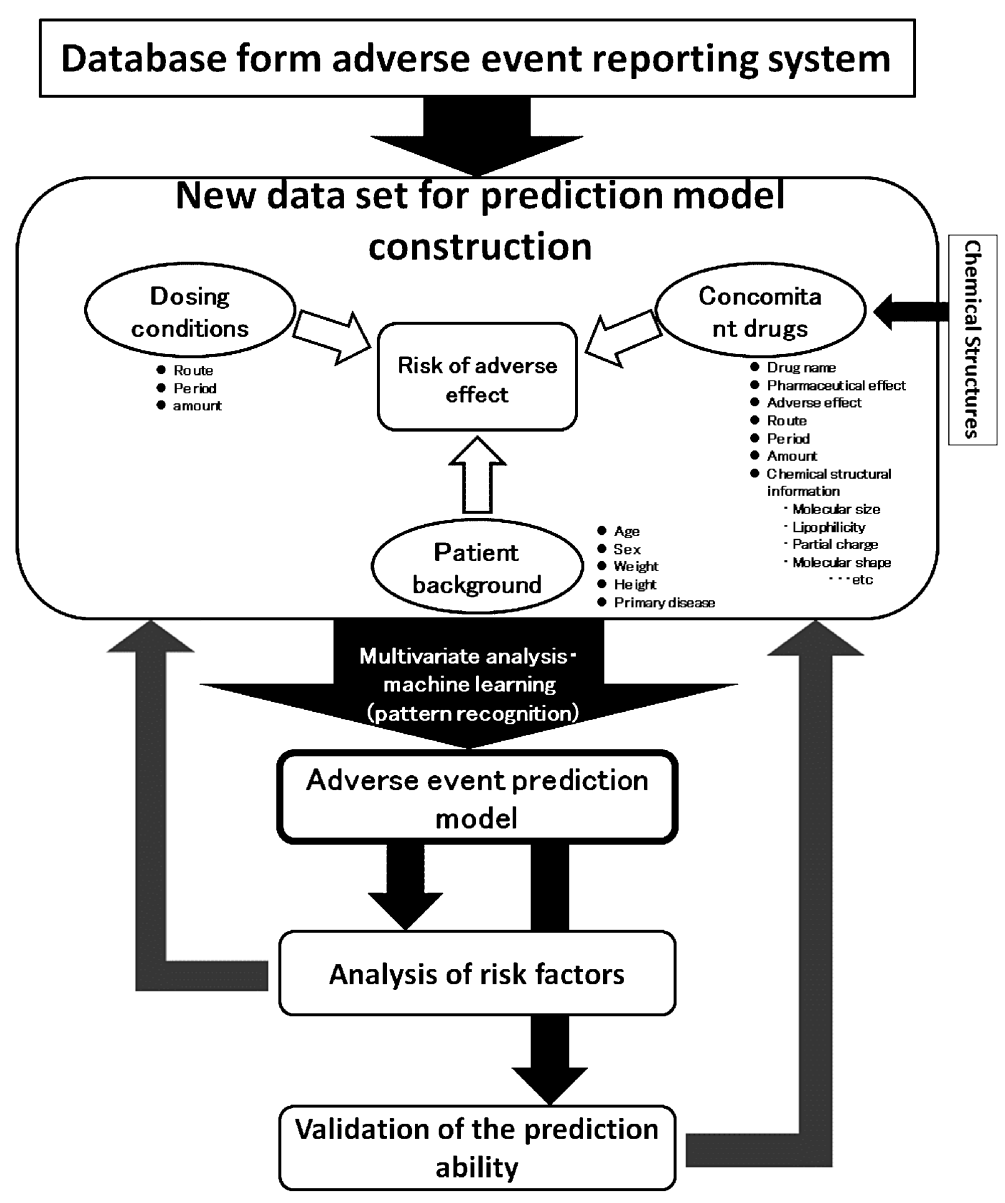

Fig. 6. Concept of the Prediction Model for Drug Adverse Event

係数の対数值（ $\log \mathrm{P} ）$ や静電的性質等の様々な数 值的特徵量（化学構造記述子）を算出し, 重回帰モ デルや PLS 回帰モデルを構築することによって化 合物ータンパク質間相互作用等に関する知見を得る ことができる。一方，計算毒性学領域では QSAR 解析と類似の解析を行うが，その予測対象は毒性で あることから定量的構造毒性相関（quantitative structure-toxicity relationship; QSTR）解析と呼ば れることもある。毒性は単一のタンパク質との相互 作用として表現することの困難な，複雑な発現経路 を伴うことが多いため，多様な薬物を対象にした予 測は困難なことが多いようである。一方，多数の記 述子を種々機械学習法に適用することによって，上 記の問題を克服した毒性関連予測モデル構築例が多 数報告されている（Fig. 5).13)

医薬品の副作用は薬物分子の毒性的側面である. 筆者らは，前述した大規模副作用データベースを援 用することによって，各医薬品の報告オッズ比など を目的変数とした定量的構造副作用相関モデルによ
る副作用予測法を提唱する．本予測法の概念を Fig. 6 に示す。データベースに掲載された患者背景情報 等に化学構造情報を加味することによって, 副作用 発現リスクの高度な予測が達成できると考える，副 作用発現リスク予測モデルは主に機械学習によるパ ターン認識により達成し, 予測能の検証を繰り返す ことによって良好な副作用予測が可能になるものと 期待している.

\section{おわりに}

医薬品の副作用は多くの場合反復投与毒性に相当 すると考えられ，その発現機序は未解明なことが多 い. 複数の有害性発現経路 (adverse outcome pathway; AOP) ${ }^{14)}$ が関与している複雑な発現機序が想定 される副作用も存在する．AOP に関する理解は化 学構造から副作用を予測する際に重要であると考え られる。計算毒性学における高度な予測モデルの構 築のためにも，未知な部分の多い毒性・副作用の AOP に関する研究がさらに発展していくことを期 待したい. 
利益相反＼cjkstart開示すべき利益相反はない。

\section{REFERENCES}

1) Nakamura M., Yakugaku Zasshi, 136, 549556 (2016).

2) Arabyat R. M., Raisch D. W., McKoy J. M., Bennett C. L., Expert Opin. Drug Saf., 14, 1653-1660 (2015) .

3) Tsutani K., Jpn. J. Clin. Pharmacol. Ther., 40, 7-16 (2009).

4) Nagai J., Uesawa Y., Kagaya H., Palliative Care Res., 10, 113-119 (2015).

5) Nagai J., Uesawa Y., Kagaya H., Palliative Care Res., 10, 161-168 (2015).

6) Nagai J., Uesawa Y., Shimamura R., Kagaya H., Clin. J. Pain, 33, 667-675 (2017) .

7) Hosoya R., Uesawa Y., Ishii-Nozawa R., Kagaya H., PLoS One, 12, e0172057 (2017).

8) Pharmaceuticals and Medical Devices Agency: $\langle$ http://www.pmda.go.jp/safety/info-services / drugs / adr-info/ suspected-adr/0005.html $\rangle$, cited 1 July, 2017.

9) Morikawa K., Bull. Natl. Inst. Health Sci., 129, 1-26 (2011).

10) Uesawa Y., Yakuzaigaku, 77, 270-274 (2017).

11) Hansch C., Maloney P. P., Fujita T., Muir R. M., Nature, 194, 178-180 (1962).

12) Hansch C., Fujita T., J. Am. Chem. Soc., 86, 1616-1626 (1964).

13) Maltarollo V. G., Gertrudes J. C., Oliveira P. R., Honorio K. M., Expert Opin. Drug Metab. Toxicol., 11, 259-271 (2015).

14) Ankley G. T., Bennett R. S., Erickson R. J., Hoff D. J., Hornung M. W., Johnson R. D., Mount D. R., Nichols J. W., Russom C. L., Schmieder P. K., Serrrano J. A., Tietge J. E., Villeneuve D. L., Environ. Toxicol. Chem., 29, 730-741 (2010). 